\title{
The Influence of Operating Strategies regarding an Energy Optimized Driving Style for Electrically Driven Railway Vehicles ${ }^{\dagger}$
}

\author{
Lukas Pröhl $^{1, * \mathbb{D}}$, Harald Aschemann ${ }^{1} \mathbb{D}$ and Roberto Palacin ${ }^{2}$ \\ 1 Chair of Mechatronics, University of Rostock, 18059 Rostock, Germany; harald.aschemann@uni-rostock.de \\ 2 Mechanical Engineering and Marine Technology, Newcastle University, Newcastle upon Tyne NE1 7RU, UK; \\ roberto.palacin@newcastle.ac.uk \\ * Correspondence: lukas.proehl@uni-rostock.de \\ + This paper is an extended version of our paper published in 2020 IEEE Congress on Evolutionary \\ Computation (CEC) (Glasgow, Scotland, United Kingdom, 19-24 July 2020) and 2019 IEEE 15th International \\ Conference on Control and Automation (ICCA) (Edinburgh, Scotland, United Kingdom, 16-19 July 2020).
}

Citation: Pröhl, L.; Aschemann, H.; Palacin, R. The Influence of Operating Strategies regarding an Energy Optimized Driving Style for Electrically Driven Railway Vehicles. Energies 2021, 14, 583. https:/ / doi. org/10.3390/en14030583

Received: 11 December 2020 Accepted: 17 January 2021 Published: 23 January 2021

Publisher's Note: MDPI stays neutral with regard to jurisdictional clai$\mathrm{ms}$ in published maps and institutional affiliations.

Copyright: (C) 2021 by the authors. Licensee MDPI, Basel, Switzerland. This article is an open access article distributed under the terms and conditions of the Creative Commons Attribution (CC BY) license (https:// creativecommons.org/licenses/by/ $4.0 /)$.

\begin{abstract}
The aim of this paper is the optimization of velocity trajectories for electrical railway vehicles with the focus on total energy consumption. On the basis of four fundamental operating modes - acceleration, cruising, coasting, and braking - energy-optimal trajectories are determined by optimizing the sequence of the operating modes as well as the corresponding switching points. The optimization approach is carried out in two consecutive steps. The first step ensures compliance with the given timetable, regarding both time and position constraints. In the second step, the influence of different operating strategies, such as load distribution and the switch-off of traction components during low loads, are analyzed to investigate the characteristics of the energy-optimal velocity trajectory. A detailed simulation model has been developed to carry out the analysis, including an assessment of its capabilities and advantages. The results suggest that the application of load-distribution techniques, either by a switch-off of parallel traction units or by a load-distribution between active units, can affect the energy-optimal driving style.
\end{abstract}

Keywords: energy-optimal trajectory planning; load distribution strategy; simulation of traction chain topologies; operating strategies; decarbonization

\section{Introduction}

For the trajectory planning of vehicles, information about the characteristics of the route ahead is highly beneficial. For autonomous driving of robots and road vehicles, the generation of maps (e.g., algorithms for simultaneous localisation and mapping (SLAM), [1]) and map-based predictions of the route (e.g., [2,3]) are currently under investigation. Furthermore, road-based traffic applications have to deal with a lot of uncertainty (e.g., unscheduled stops, traffic jams, or unknown routes), which affects the driving style. In contrast, the most important operating conditions for railway traffic are almost known in advance. Here, e.g., distances, arrival and departure times, speed limits, and traffic stops, as well as altitude and tunnel profiles can be considered beforehand. The trajectory planning for railway applications strongly profits from predetermined knowledge about duty cycles and their characteristics. Based on these, a driving time is scheduled based on timetabling techniques (e.g., [4]). Thus, the scheduled time reserve between a time-optimal solution (all-out trajectory) and the desired driving time, according to the timetable, may be utilized to optimize the driving style with regard to several objectives. Here, the reduction of mechanical wear, the mitigation of local noise pollution, or-as the main objective of this paper-the lowering of the energy consumption, can be of major interest.

For the determination of the energy-optimal velocity profile, a lot of approaches have been published in the past. Representing a very common technique for this kind of applica- 
tion, dynamic programming and sequential quadratic programming were applied in [5-7]. To avoid the high calculation effort of these techniques, model-based approaches were proposed. Here, a model-based heuristic was considered where a set of free parameters was determined by optimization techniques. This heuristic was based on the assumption that the energy-optimal trajectory involves four driving modes (see Figure 1), namely:

- Acceleration-determined by the maximum traction effort and the passenger comfort acceptance levels;

- Cruising-motion at a constant velocity level (no acceleration);

- Coasting-motion without active traction or braking at the wheels;

- Braking-determined by the maximum braking effort as well as the passenger comfort acceptance levels.

The arrangement of these driving modes characterizes different driving strategies. In [8], a simulation model was developed and validated with real-life driving profiles, to assess the effect of the driving profiles regarding the performance of a railway network. For energy-optimal trajectory planning, the switching-points have to be optimized for the purpose of finding a trade-off between the maximization of the duration of coasting (no active propulsion) on the one hand and the avoidance of high aerodynamic resistance forces for high velocities on the other hand.

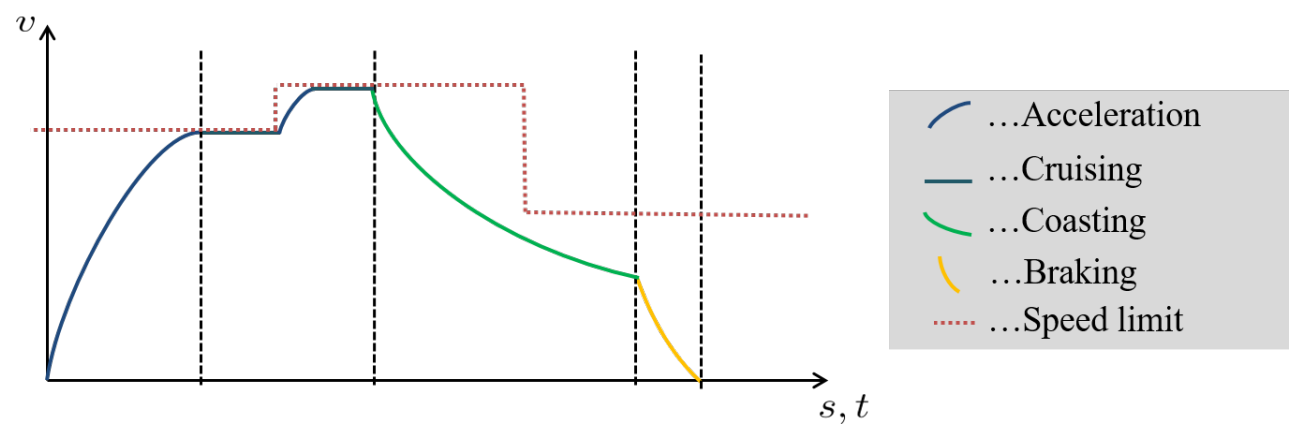

Figure 1. The four driving modes — acceleration, coasting, cruising, braking.

This model-based optimization approach was implemented for hybrid trains in $[9,10]$. Moreover, the authors of [11] employed this technique to implement a multi-objective optimization regarding safety requirements, passenger comfort, and dynamic performance. In [12], the energy-optimal setting for the switching of the driving states was determined in one optimization step only. Here, an objective function was defined that accounted for the total energy consumption, whereas additional penalty functions addressed both time and position constraints given by the timetable. As the resulting optimization problem could take a non-convex form and as the calculation of gradient information with respect to the objective function may become difficult or even impossible due to discontinuities, a particle swarm optimization (PSO) was carried out in [12].

To increase the accuracy as well as to reduce the calculation effort, a two-step optimization approach was proposed in [13]. As the current work is based on this approach, the model-based heuristic as well as the two-step optimization approach will be briefly summarized this paper.

Nevertheless, the driving style is not the only means to save energy within a traction chain topology of a railway vehicle. This paper considers strategies that are applicable if the traction chain is in low-load operation. Especially during coasting and cruising phases, as well as during standstill at stations, the required traction power is very small. The efficiency for the electrical components, however, decreases for this low-load operation. To mitigate this issue at a low efficiency level, the load can be distributed between different traction components, either by a shift of the load or by a partial switch-off of traction components. This technique of a load distribution is well-known for the application within hybrid traction structures. For instance, in [14,15], a sensitivity-based optimization technique was utilized to minimize the energy losses for diesel-electric railway vehicles. 
However, this technique is also applicable for pure electrical traction topologies with multiple traction units.

A detailed simulation model of the total traction chain of the vehicle is described in Section 2 and the two-step optimization approach is proposed in Sections 3 and 4. The load distribution between the parallel traction units is presented in Section 5 and the influence of these operating strategies regarding the energy-optimal driving style is analyzed in Section 6 . Section 7 provides a set of conclusions based on the work carried out.

\section{Simulation Model of the Railway Traction Chain}

The analysis and assessment carried out in this paper are based on the simulation results of a detailed single-train simulation model [16] verified and validated by industrial stakeholders from the railway sector [17]. The implemented simulation parameters present a generic traction topology for a high-speed service vehicle. The corresponding parameters are elaborated in [18] and are summarized in Tables A1 and A2.

In this paper, the simulation model of an AC power supply traction topology for an electrically driven railway vehicle is considered (see Figure 2). The presented optimization approach and operating strategies, however, are not limited to this scenario. It is also applicable to alternative traction chain characteristics, including different electrical trains with a DC power supply topology or fuel-cell powered traction chains, as well as for hybrid trains including an internal combustion engine.

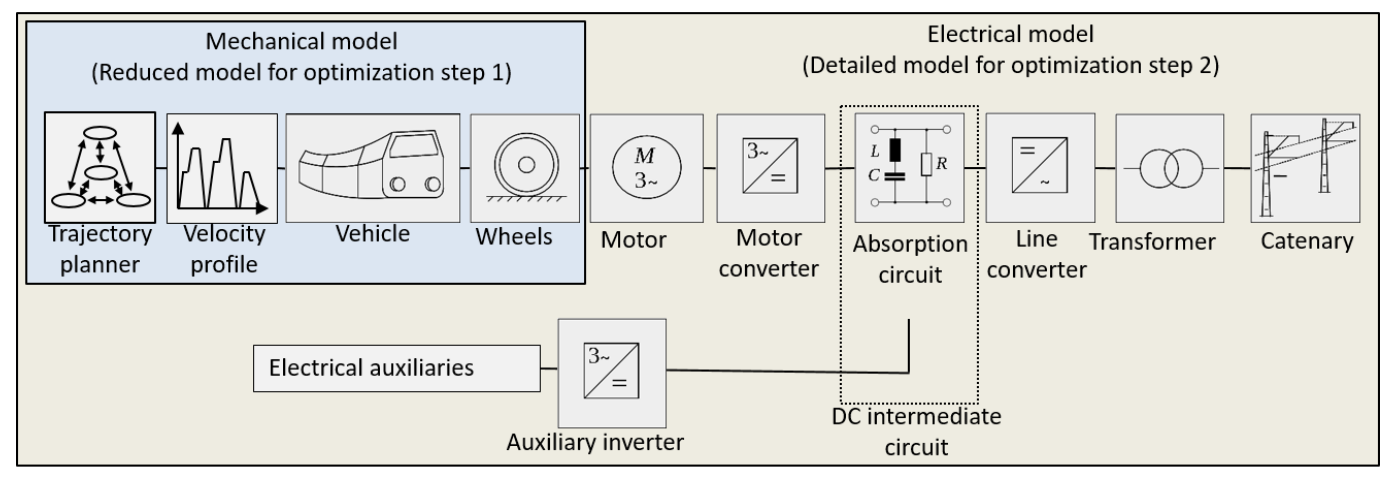

Figure 2. Detailed simulation model of an electrically driven railway vehicle with AC power supply.

For a fast and realistic calculation of the energy consumption of the total traction chain, the implementation of a backward simulation structure is advantageous (see [19]). For the backward simulation, the reverse direction of the physical power flow is evaluated within a block structure of the traction chain (see Figure 2).

The main objective of the trajectory planning module, which is the topic of Section 3, is the determination of a proper desired speed profile as an input of the simulation chain. Then, the corresponding inputs signals follow from the inverse dynamics of the traction chain represented by the backward simulation topology. From a control point of view, this is equivalent to a flatness-based approach and the solution of an inverse problem.

The optimization approach presented here is separated into two steps. In the first step, only the mechanical model is considered. The electrical part, however, is additionally taken into account within the second step.

\subsection{Mechanical Model of the Train}

According to Figure 3, the differential equation for the mechanical behavior of the vehicle can be stated by

$$
k_{\text {rot }} M \dot{v}=F_{\text {wheel }}-F_{\text {res }}-F_{\text {inc }} .
$$

Here, the inertia of the train is considered by the total mass of the train $M$, where the factor $k_{\text {rot }}$ accounts for the additional rotary masses of the traction chain. 


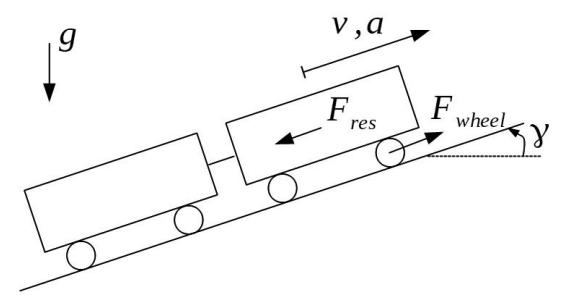

Figure 3. Scheme of the mechanical vehicle characteristics.

The driving resistances $F_{\text {res }}$ involve the aerodynamic drag and the rolling resistance, as well as mechanical windage and bearing losses throughout the traction chain, and are jointly stated with the Davis equation,

$$
F_{r e s}=c_{0}+c_{1} v+c_{2} v^{2}
$$

which is a common approach for approximating the total running resistances of a train (see [20]). This approximation comprises three coefficients $\left(c_{0}, c_{1}, c_{2}\right)$ describing the overall resistance as a second-degree polynomial of the vehicle velocity $v(t)$. The inclination $\gamma$ defines the inclination force

$$
F_{i n c}=M \sin (\gamma) g \text {. }
$$

The force at the wheel $F_{\text {wheel }}$ represents the total traction (braking) force, delivered by the traction motors. In analogy to the characteristics of the traction motors, the traction force is described by the diagram shown in Figure 4 .

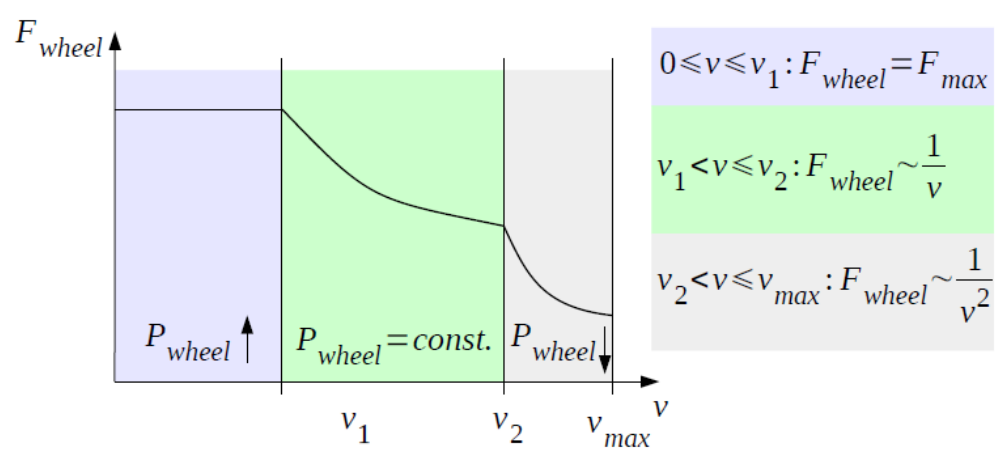

Figure 4. Traction force as a function of the vehicle velocity (see [21]).

During the low-speed operation $\left(0 \leq v \leq v_{1}\right)$, the maximum traction (braking) power is available to accelerate (decelerate) the vehicle. If the train velocity exceeds the velocity $v_{1}$, the traction motors operate in a field-weakening mode, and the resulting force at the wheel decreases proportional to the reciprocal of the train velocity. This velocity range $\left(v_{1}<v \leq v_{2}\right)$ represents the mode with a constant power at the wheel. With a further increase of the train velocity, it is also possible to reach the high-speed operation (for $v_{2}<v \leq v_{\max }$ ). To increase the velocity, the power of the traction motors has to account for a further reinforcement of the field weakening. In this high-speed mode, the power at the wheel is proportional to $1 / v^{2}$ (see [21]).

Based on the resulting traction force $F_{\text {wheel }}$, the traction power $P_{\text {wheel }}$ at the wheels is given by

$$
P_{\text {wheel }}=F_{\text {wheel }} \cdot v \text {, }
$$

which is in compliance with the tracking of the desired speed profile. The force as well as the power at the wheel can be related by the axle gear characteristics to the motor torque 
and the mechanical power of the traction motors. Thus, the traction motors represent the interface to the electrical part of the model.

\subsection{Electrical Model of the Traction Chain}

To account for the individual energy losses of the included electric traction components (motor, motor inverter, absorption circuit, line converter, transformer, auxiliary converter), appropriate efficiency maps are utilized. Here, the efficiency map for the $i$-th component is implemented either as a function of the current load power, i.e., $\eta_{i}=f\left(P_{\text {load, } i}\right)$ (e.g., for the transformer), or with dependence on both load power and angular velocity, i.e., $\eta_{i}=$ $f\left(P_{\text {load }, i}, \omega_{i}\right)$ (e.g., for the electric motor), see Figure 5.

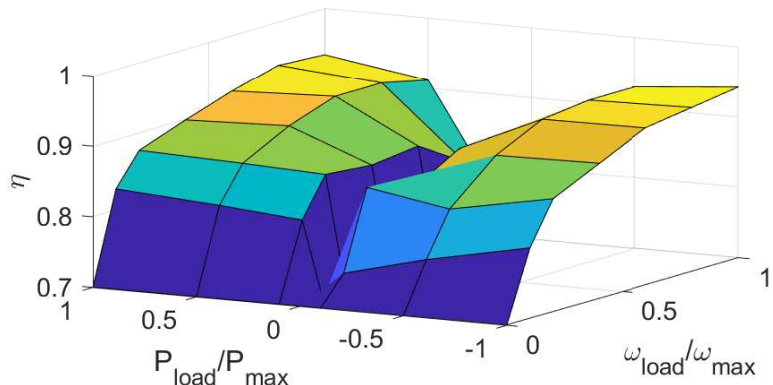

(a) Efficiency map of the applied induction motor as a function of load power and angular velocity.

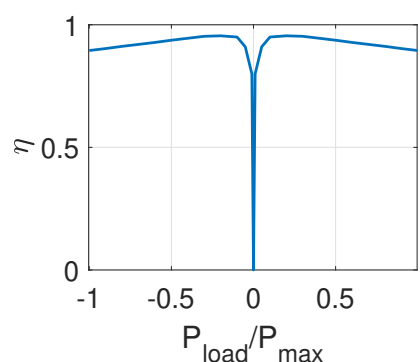

(b) Efficiency curve of the applied transformer with dependence on the load power.

Figure 5. Implementation of the efficiency maps.

To avoid the evaluation of the efficiency maps for low-load operation, the simulation topology includes a dedicated approach to handle idle and low-load operations. For each component $i$, an idle power loss $P_{i d l e, i}$ is defined and, thus, the resulting input power $P_{i n, i}$ for the $i$-th components follows as

$$
P_{i n, i}= \begin{cases}\frac{1}{\eta_{i}} P_{\text {load }, i} & \text { if } \quad \frac{1}{\eta_{i}} P_{\text {load }, i}>P_{\text {idle }, i}, \\ P_{\text {idle }, i} & \text { else. }\end{cases}
$$

The total energy loss of a single component is summarized in Figure 6.
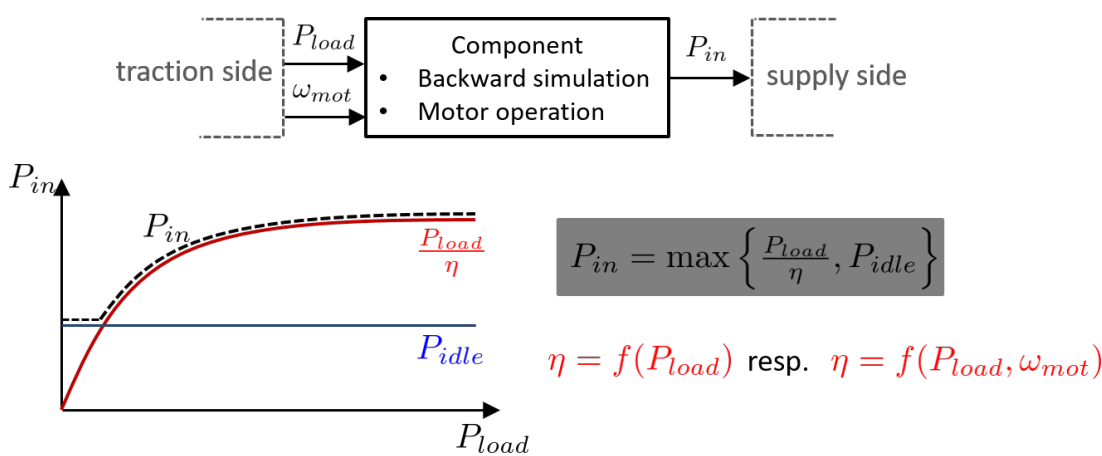

Figure 6. Power loss for a single traction component (see [21]).

As each single component exhibits such an idle loss, the number of traction components used has to be decreased to minimize the total idle loss of the traction chain. As a result, the proposed strategy of deactivating single traction components allows for a significant potential optimization of the total energy consumption and is presented in detail in Section 5.

In addition to the energy losses of the traction components, the energy consumption of the auxiliaries is also included in the assessment. Within this simulation model, the aux- 
iliary power is required, among other purposes, for the power profile for the heating, ventilation, and air conditioning (HVAC) systems and the power request for electrical on-board devices, as well as the cooling power profile for the cooling systems of the traction components.

Please note that the implemented simulation model is parametrized according to the generic railway models that are defined in [18] for different railway services.

\section{Functionality of the Trajectory Planning Module}

The heuristic employed in the trajectory planning module was elaborated in previous work (see e.g., $[9,12,13])$. For completeness and in order to facilitate understanding of this paper, the basic technique of this heuristic is summarized in this section.

An exemplary combination of the different driving modes is shown in Figure 7.
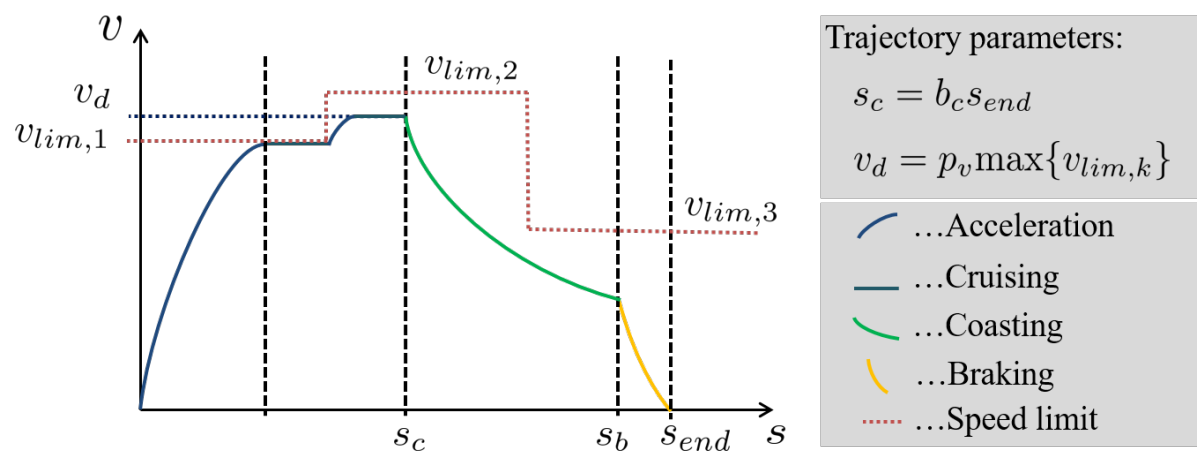

Figure 7. Exemplary trajectory profile based on four characteristic driving modes (see [13]).

As indicated in Figure 7, the optimal switching points between the driving modes correlate with a trade-off between the maximum velocity and the amount of coasting. Accordingly, the parameter $b_{c}$ defines the coasting distance $s_{c}$, whereas the parameter $p_{v}$ characterizes the maximum desired velocity.

Here, on the one hand, the coasting distance is stated with

$$
s_{c}=b_{c} s_{\text {end }} \text { with } b_{c} \in\left[b_{c, \min }>0 ; b_{c, \max }<1\right],
$$

where $s_{\text {end }}$ is the given distance towards the next station. On the other hand, the desired maximum velocity $v_{d}$ of the travel segment is defined by

$$
v_{d}=p_{v} \max \left\{v_{\text {lim, }, k}\right\} \text { with } p_{v} \in\left[p_{v, \min }>0 ; 1\right] .
$$

Here, $v_{\text {lim, }, k}$ state the different segment-specific speed limits. The braking distance $s_{b}$ is calculated by an evaluation of the equation of motion (1) in a backward-time direction using the maximum braking effort available. This distance denotes the maximum distance possible to initialize braking according to given distance and velocity constraints for the next stop or the next speed limit. Here, $v_{b}$ denotes the velocity, which has to be reached with the braking $\left(v_{b}=0\right.$ for a stop, or $v_{b}=v_{l i m, k+1}$ to be in compliance with the next speed limit). The coasting distance $s_{c}$, as well as the maximum desired velocity $v_{d}$, are utilized to implement the switching strategy as depicted in Figure 8. 


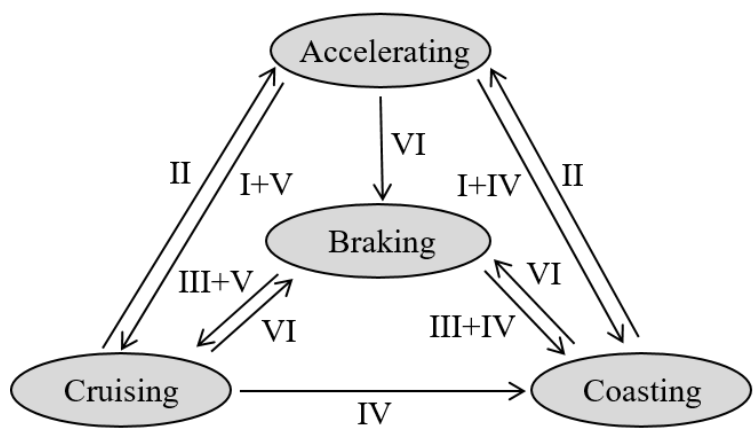

Switching Conditions:
I. $\quad\left(v=v_{d}\right) \vee\left(v=v_{\text {lim }}\right)$
II. $\left(v<v_{d}\right) \wedge\left(v<v_{\text {lim }}\right)$
III. $\left(v \leq v_{b}\right) \wedge\left(v_{b} \neq 0\right)$
IV. $\left(s \geq s_{c}\right)$
V. $\left(s<s_{c}\right)$
VI. $\left(s \geq s_{b}\right) \wedge\left(v>v_{b}\right)$

Figure 8. Structure and switching conditions of the trajectory planning module.

The application of the switching conditions by the trajectory planning module allows for several trajectory profiles. Here, the possible switching conditions depend on the current driving state, e.g., during coasting, only the switching conditions II and VI are admissible. To illustrate the functionality of the trajectory planner, a simple example with only one speed limit is given in Figure 9.

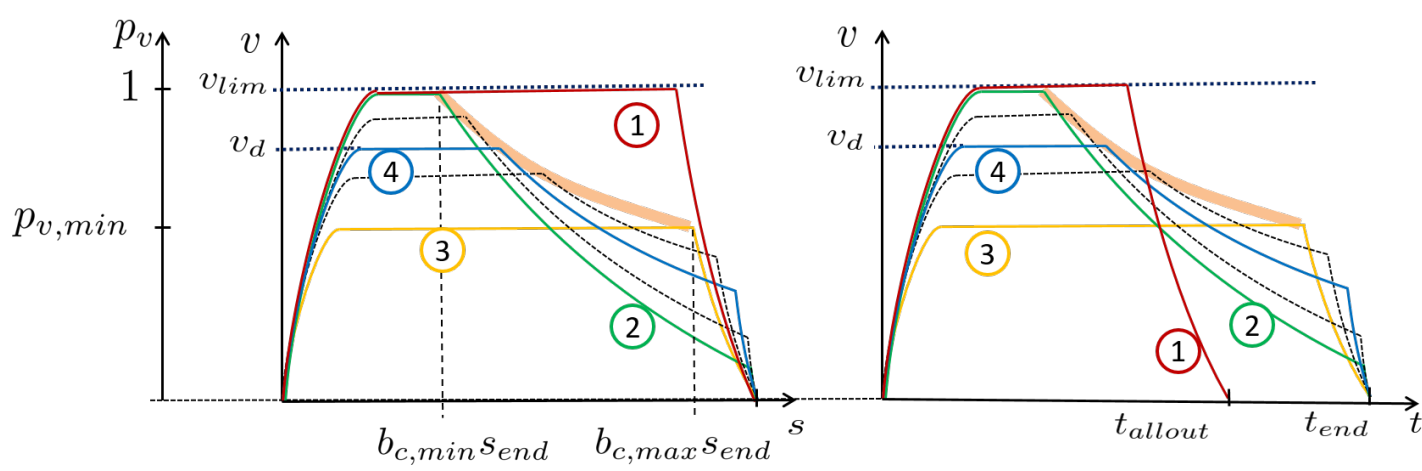

Trajectory modes:

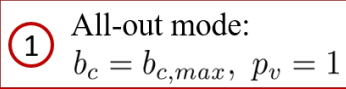

(2) Maximize coasting:

(2) $b_{c}=?, p_{v}=1$

(3) No coasting:

(3) $b_{c}=b_{c, \max }, p_{v}=$ ?

(4) Energy optimal:

(4) $b_{c}=$ ?, $p_{v}=$ ?

Figure 9. Trajectory modes for different driving strategies presented in the time and distance domains.

To express the functionality of the trajectory planner approach, the time-optimal profile is shown by the red characteristic. The time-optimal solution, which is denoted as the allout mode, is the resulting trajectory profile, based on the parameter combination $p_{v}=1$ and $b_{c}=1$. This driving strategy does not include any coasting and fully exploits the maximum speed limit. However, this time-optimal profile is not compliant with the desired arrival time of the timetable. In contrast, all other depicted velocity profiles fulfill the timetable request. The objective of the optimization approach is to determine the energy-optimal solution within this set. For the given example, it becomes obvious that the energy-optimal solution (blue line) is located in between the two following driving strategies:

- The maximization of coasting (green line) — the maximum velocity is utilized, which is achieved by choosing $p_{v}=1$, and the desired time reserve is used for coasting.

- No coasting is applied (yellow line) and the maximum velocity is reduced to meet the timetable. Accordingly, the parameter defining the coasting distance is set to the maximum value $b_{c}=b_{c, \max }$ (with $s_{c, \max }=b_{c, \max } \cdot s_{\text {end }} \geq s_{b}$ ), whereas the parameter $p_{v}$, specifying the admissible maximum velocity, has to be determined.

The possible parameter combinations meeting the timetable are indicated by the bold orange line in Figure 9. This set of solutions is calculated within step I of the optimization approach presented in Section 4, whereas the global solution is determined within a second step.

Maximizing coasting is a commonly used driving strategy of the rail vehicle operators and therefore used as a reference scenario in this paper. 
The presented railway scenario in this work is a high-speed train with a maximum speed limit of $250 \frac{\mathrm{km}}{\mathrm{h}}$. This scenario presents a generic service profile for a high-speed service, which is elaborated in detail in $[16,18]$. The resulting reference velocity profile is given in Figure 10.

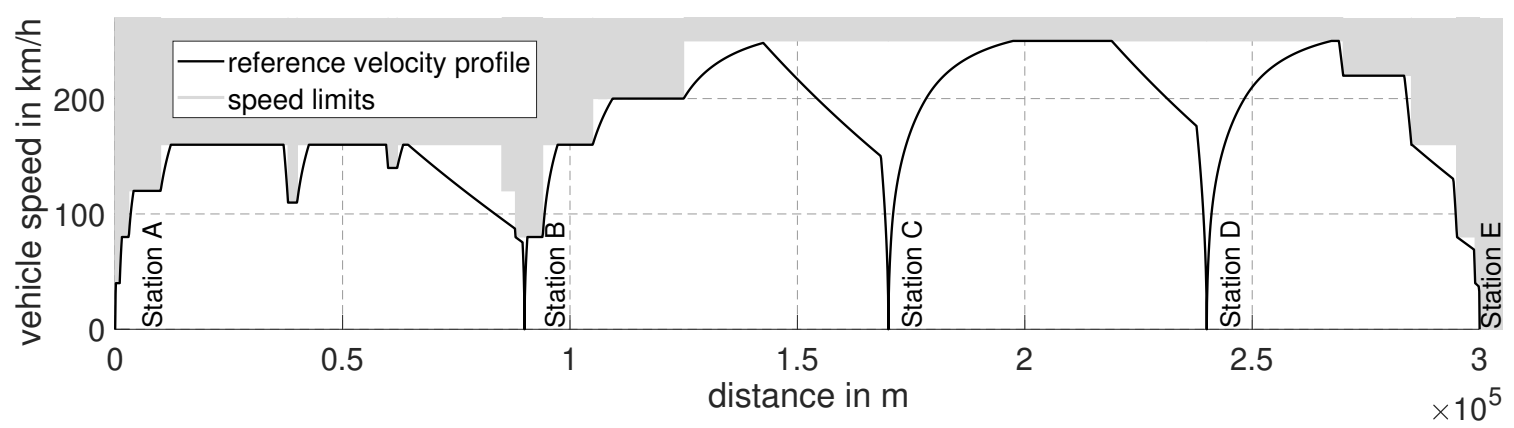

Figure 10. Reference velocity profile for the presented high-speed 250 railway scenario.

As indicated in the figure, there are four stations with a total distance of $300 \mathrm{~km}$. The speed limits are presented in light gray. The total travel time is given by $t_{A E}=02: 06$ (hh:mm), including standstills of $3 \mathrm{~min}$ at each station.

\section{Energy-Optimal Driving Strategy}

This section provides an overview of the two-step optimization strategy applied, which was developed in [13]. The first step of this strategy determines the boundaries of feasible solutions, reflecting both position and time constraints of a given timetable. To minimize the calculation effort, only the mechanical part of the model is applied for the simulations within this step (see Figure 2). The objective function $J_{I}$ for this step is given by

$$
J_{I}=\left\{\begin{array}{cl}
J_{t}+J_{s} & \text { if } \quad J_{t} \neq 0 \vee J_{s} \neq 0, \\
J_{0} & \text { else. }
\end{array}\right.
$$

The penalty terms $J_{t}$ and $J_{s}$ reflect the time and position constraints of the timetable, considering the desired departure and arrival times $t_{0}, t_{f}$, as well as the corresponding positions $s_{0}, s_{f}$. The penalty terms are chosen as

$$
J_{s}=\left\{\begin{array}{cl}
\left(s_{d r}-\left(s_{f}-s_{0}\right)\right)^{2} & \text { if }\left|s_{d r}-\left(s_{f}-s_{0}\right)\right|>\Delta s, \\
0 & \text { else, }
\end{array}\right.
$$

and

$$
J_{t}=\left\{\begin{array}{cl}
\left(t_{d r}-\left(t_{f}-t_{0}\right)\right)^{2} & \text { if } \quad\left|t_{d r}-\left(t_{f}-t_{0}\right)\right|>\Delta s, \\
0 & \text { else. }
\end{array}\right.
$$

Here, the admissible time and position differences $\Delta s$ and $\Delta t$ are taken into account. These penalty functions utilizes the calculated driving time $t_{d r}$ as well as the driving distance $s_{d r}$, which are determined using only the reduced mechanical model of the train, according to Figure 2.

The resulting objective function is characterized by a flat region (with vanishing gradients) within the non-constrained search space. The term $J_{0} \leq 0$ in Equation (8) characterizes the value of the flat region of the objective function, where no active timetable constraints are applied.

To determine the boundaries of this flat region, in [13] a multi-modal optimization technique was proposed. As it is a well known and approved technique to solve gradient-free, multi-modal optimization problems, a slightly modified firefly algorithm (FFA) according 
to [22] was chosen. It is worth noting that this approach is also applicable to more than one coasting section, e.g., before attaining speed limits or gradient sections. Consequently, the dimension of the optimization problem would increase, but the optimization strategy would remain the same. However, in order to create a simpler graphical representation of this approach, only the case with one coasting point is presented. Alternatively, a gridbased approach can be applied by solving a one-dimensional optimization problem for a given grid of $b_{c}$-values $\left(b_{c} \in\left\{b_{c, \min }, b_{c, \max }\right\}\right)$. Here, the suitable parameter $p_{v a}$ can be determined, for example, by means of bisection techniques. result in

Finally, the solutions minimizing the cost function $J_{I}$ of the first optimization step

$$
\left[p_{v}^{I}, b_{c}^{I}\right]=\arg \left\{\min _{p_{v}, b_{c}}\left\{J_{I}\left(p_{v}, b_{c}\right)\right\}\right\}
$$

This set $\left[p_{v}^{I}, b_{c}^{I}\right]$ of parameter combinations is now utilized to define a representative parameter space where all the timetable constraints are fulfilled. For the presented railway scenario, the parameter sets for the different sections are determined according to Figure 11.
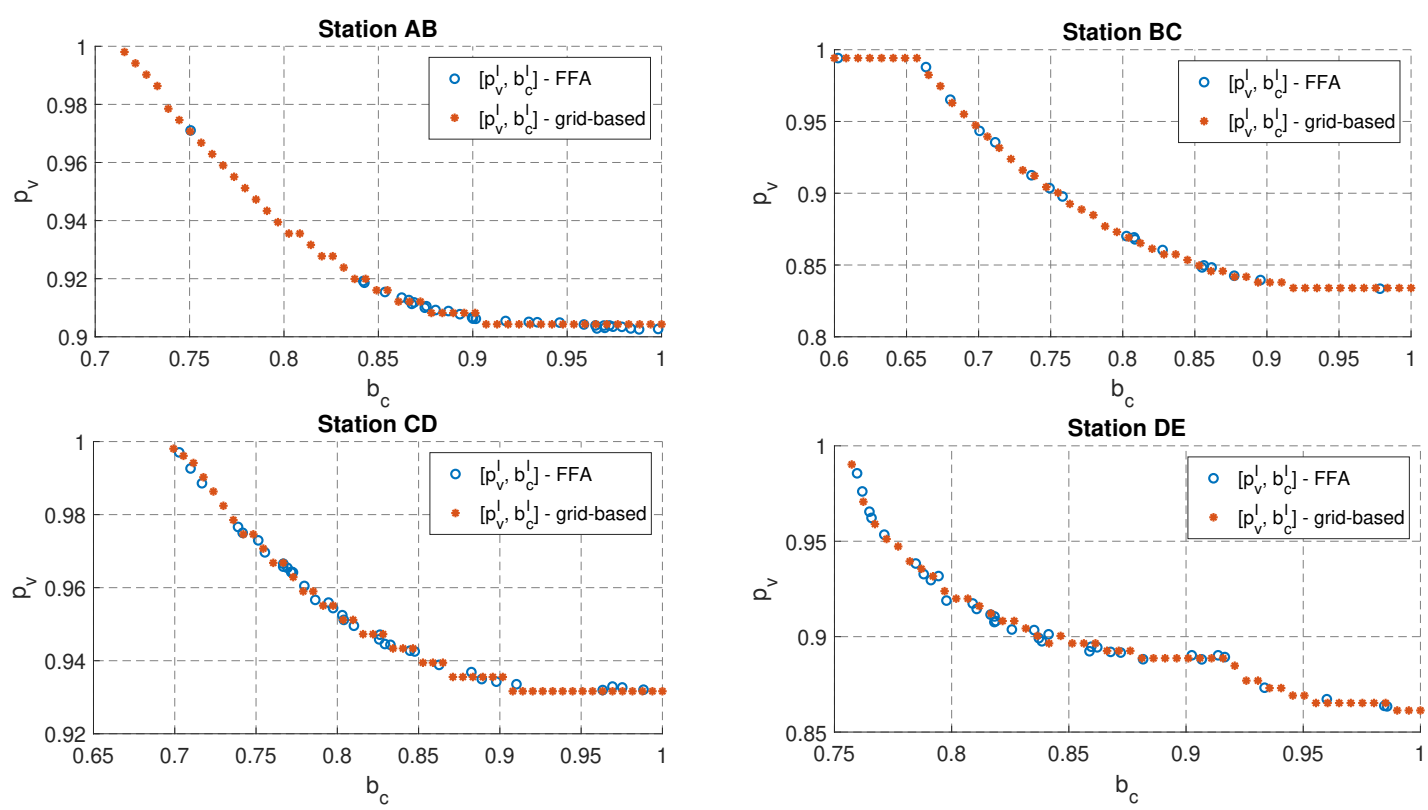

Figure 11. Solutions of the first optimization step for solving the optimization problem according to Equation (11) for different sections.

Here, the firefly approach (FFA, according to [13]) is compared to the grid-based evaluation. It becomes apparent that both techniques allow for a proper calculation of the admissible solutions.

In the second optimization step, the energy-optimal velocity profile is determined. Here, the heavily reduced search space allows for a smaller calculation effort. Hence, the objective function for the second step is related to the total net energy of the train

$$
J_{I I}=E_{\text {total }}=E_{\text {cons }}-E_{\text {rec }} .
$$

Here, the total net energy is the sum of the energy taken from the net $E_{\text {cons }}$ and the recuperated one $E_{r e c}$. For the determination of the energy $E_{c o n s}$ and the recuperated energy $E_{r e c}$, the detailed simulation model of the total electrical traction chain according to Figure 2 is employed to calculate the energy consumption for a specific track and train characteristic. 
In analogy to the fist optimization step, the gradient information for this problem is also not available, and gradient-free optimization techniques have to be applied. The evaluation of a suitable optimization technique leads to the corresponding solutions

$$
\left[p_{v}^{I I}, b_{c}^{I I}\right]=\arg \left\{\min _{p_{v} \in p_{v}^{I}, b_{c} \in b_{c}^{I}}\left\{J_{I I}\left(p_{v}, b_{c}\right)\right\}\right\}
$$

of the second step. The optimal solution for the driving strategy is illustrated in Figure 12. Here, the trade-off between the applied maximum velocity and the amount of coasting results in the depicted trajectories.

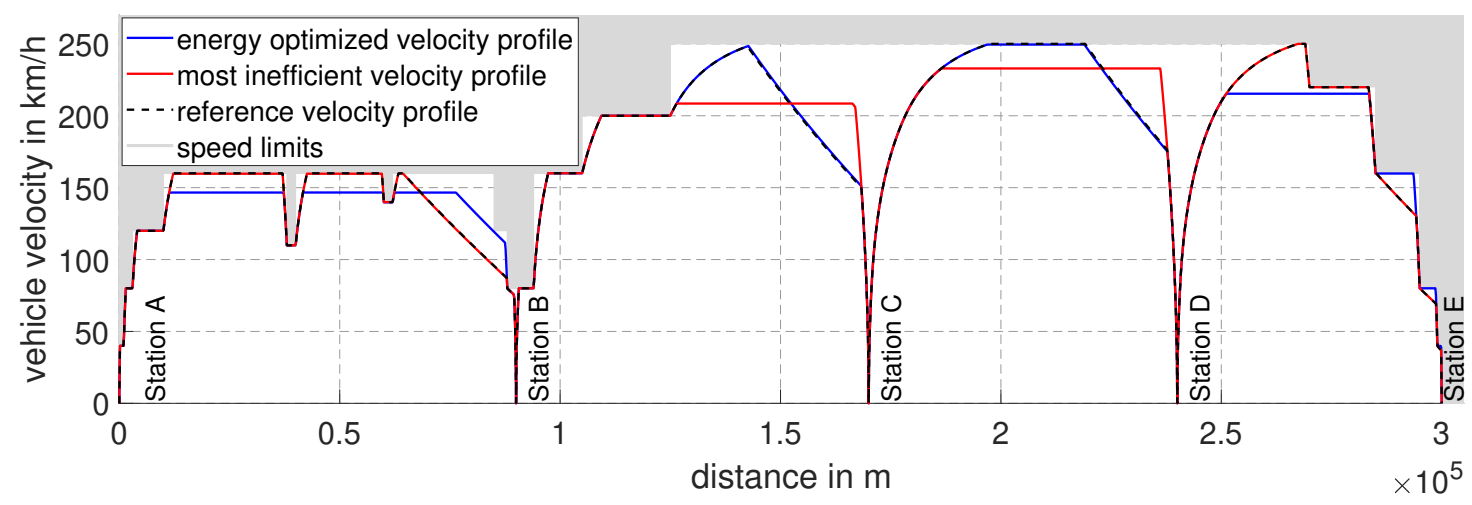

Figure 12. Optimized driving strategy for the presented service profile.

To underline the energy-saving effect of the optimized driving strategy, the sectionby-section energy consumptions are summarized in Table 1.

Table 1. Energy savings due to the energy-optimal driving style.

\begin{tabular}{|c|c|c|c|c|c|}
\hline \multirow[b]{2}{*}{ Segment } & \multicolumn{3}{|c|}{ Energy Consumption in $\mathrm{kWh}$} & \multirow{2}{*}{$\begin{array}{l}\text { Total Energy } \\
\text { Savings in kWh } \\
\text { (opt. vs. ref.) }\end{array}$} & \multirow{2}{*}{$\begin{array}{l}\text { Total Energy } \\
\text { Savings in \% } \\
\text { (opt. vs. ref.) }\end{array}$} \\
\hline & $\begin{array}{l}\text { Reference } \\
\text { Trajectory }\end{array}$ & $\begin{array}{l}\text { Optimized } \\
\text { Trajectory }\end{array}$ & $\begin{array}{l}\text { Most Inefficient } \\
\text { Trajectory }\end{array}$ & & \\
\hline Station $\mathrm{AB}$ & 945 & 902 & 945 & $\approx 43$ & $\approx 4.5$ \\
\hline Station BC & 1080 & 1080 & 1167 & $\approx 0$ & $\approx 0$ \\
\hline Station CD & 1158 & 1158 & 1269 & $\approx 0$ & $\approx 0$ \\
\hline Station DE & 1011 & 946 & 1011 & $\approx 65$ & $\approx 6.4$ \\
\hline Total net energy & 4194 & 4086 & 4392 & $\approx 108$ & $\approx 2.5$ \\
\hline
\end{tabular}

For the Sections 1 and 4 (drive cycles between Station $\mathrm{AB}$ and Station DE, respectively), the energy-optimized velocity profile results in energy savings of about $5 \%$. However, for Sections 2 and 3 (drive cycles between Station BC and Station CD, respectively), the energyoptimized velocity profile is equivalent to maximizing coasting, which is considered as the reference solution.

It is also worth pointing out that for Sections 1 and 4 the maximization of coasting, which is the commonly used technique by railway operators, represents the most energyinefficient driving style.

\section{Operating Strategies to Minimize Low-Load Operation and Idle Losses}

A further method for decreasing energy consumption is the application of in-vehicle operating strategies to avoid low-load operation and idle losses of the electrical traction components. This technique is based on the fact that a common railway traction topology is composed of various traction chains working in parallel. A representative arrangement of 
the traction components is depicted in Figure 13. Here, the number of traction components within the traction chain is indicated in a schematic manner.

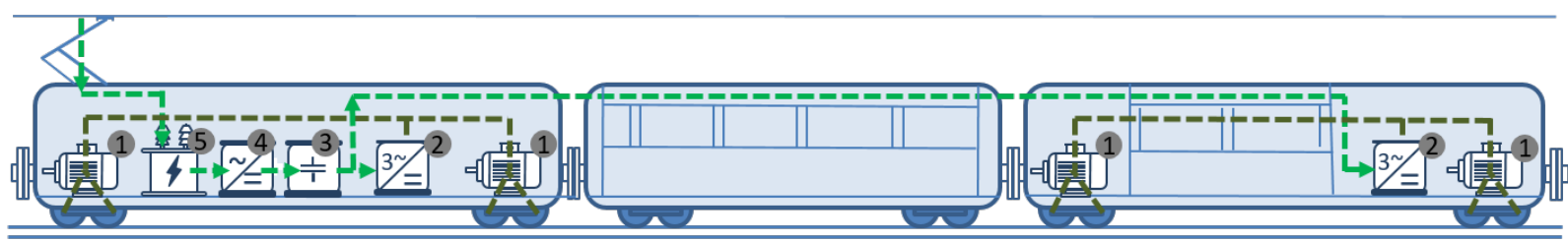

Traction motor

Traction inverter

Absorption circuit at the DC intermediate circuit
Line converter ----- Energy flow between the catenary

5 Transformer and the traction inverters

-- - Energy flow between the traction inverters and the wheels

Figure 13. Schematic arrangement of the traction components.

As presented for example in Figure 13, one transformer powers several traction inverters (in Figure 13, the total number of traction inverters is $n_{i n v, t o t a l}=2$ ), whereas one traction inverter provides the energy supply of several traction motors (e.g., in Figure 13 the total number of traction motors is $n_{\text {mot,total }}=4$ ). Thus, the ratio between the total number of traction motors and inverters is given by

$$
r=\frac{n_{\text {mot,total }}}{n_{\text {inv, total }}}, \text { with } r \in \mathbb{N} \backslash\{0\} .
$$

As mentioned above, the energy losses of the electrical traction components according to Figure 6 are defined by the corresponding efficiency maps and idle losses. As presented in Figure 5, the efficiency for the single components decreases during low-load operation. To avoid an operation with poor efficiency, the total traction load request $P_{\text {total }}$ can be shifted between the components either by a partial switch-off of single traction units or a load-distribution without a total switch-off of traction components. These two operation strategies can either be applied separately or combined, which leads to more efficient operation (see Figure 14). In the example illustrated in Figure 14, the total power request can either be fulfilled by four components, operating at a low efficiency level $\mu_{1}$, or by only one component, operating at a high efficiency $\mu_{2}$.

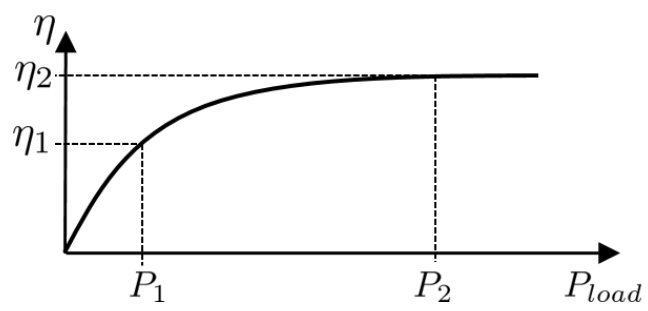

$$
\begin{aligned}
& \text { Example }-4 \text { total components: } \\
& \begin{array}{l}
P_{\text {total }}=4 \cdot P_{1} \\
P_{\text {total }}=P_{2}
\end{array}
\end{aligned}
$$

Figure 14. Component efficiency for different loads.

It is important to mention that within this paper the load distribution between total traction units is considered. As a traction unit, a single traction inverter in combination with the corresponding traction motors is defined (e.g., in Figure 13, one traction inverter 2 is linked with two traction motors (1). Accordingly, a switch-off of a single traction motor as well as the switch-off of transformers or line converters is not considered in this work, because it is difficult to apply in real-world scenarios.

For the switch-off operating strategy, the number of the applied traction motors $n_{m o t}$ and traction inverters $n_{i n v}$ can be stated as

$$
n_{\text {inv }}=\left\lceil\frac{T_{\text {mot,total }}}{T_{\text {mot, } m a x}\left(\omega_{\text {mot }}\right) \cdot r}\right\rceil \text { and } n_{\text {mot }}=n_{\text {inv }} \cdot r,
$$


by evaluating the total torque request $T_{\text {mot,total }}$ for the total traction drive and the maximum traction torque $T_{\text {mot,max }}\left(\omega_{\text {mot }}\right)$ of a single traction motor (the operator $\lceil\ldots\rceil$ represents the ceiling). In analogy to the evaluation of the traction force in Figure 4, the maximum torque of a traction motor depends on the motor speed $\omega_{\text {mot }}$. Conclusively, the maximum motor torque $T_{\max , \operatorname{mot}}$ decreases during high-speed phases of the train as a result of fieldweakening effects.

According to the specification in Equation (15), the possibility to switch-off all components $\left(n_{\text {inv }}=n_{\text {mot }}=0\right)$ is considered suitable for vanishing torque requests $\left(T_{\text {mot,total }}=0\right)$. This state occurs during the standstill at the station as well as during coasting sections. However, it is worth mentioning that the complete switch-off of traction units may occur in an increased wear of the mechanical traction components (among others the bearing and axle gears) of the traction motors, if the traction motors run in a torque-free operation.

To avoid this effect, a load distribution without a switch-off of the traction components is presented.

For the distribution of the required load, a vector of splitting factors

$$
\underline{s}=\left[s_{1}, \ldots, s_{i}, \ldots, s_{n_{\text {inv }}}\right]^{T}, \quad i \in\left\{1, \ldots, n_{\text {inv }}\right\}, \sum_{i}^{n_{\text {inv }}} s_{i}=1,
$$

is defined to calculate the proportion of the applied power

$$
P_{i, \text { mot }}=\frac{s_{i}}{r} \cdot P_{\text {mot, total }} \text { and } P_{i, \text { inv }}=s_{i} \cdot P_{\text {mot,total }} \cdot \frac{1}{\eta_{1, \text { mot }}}
$$

for the $i$-th traction unit (see Figure 15).

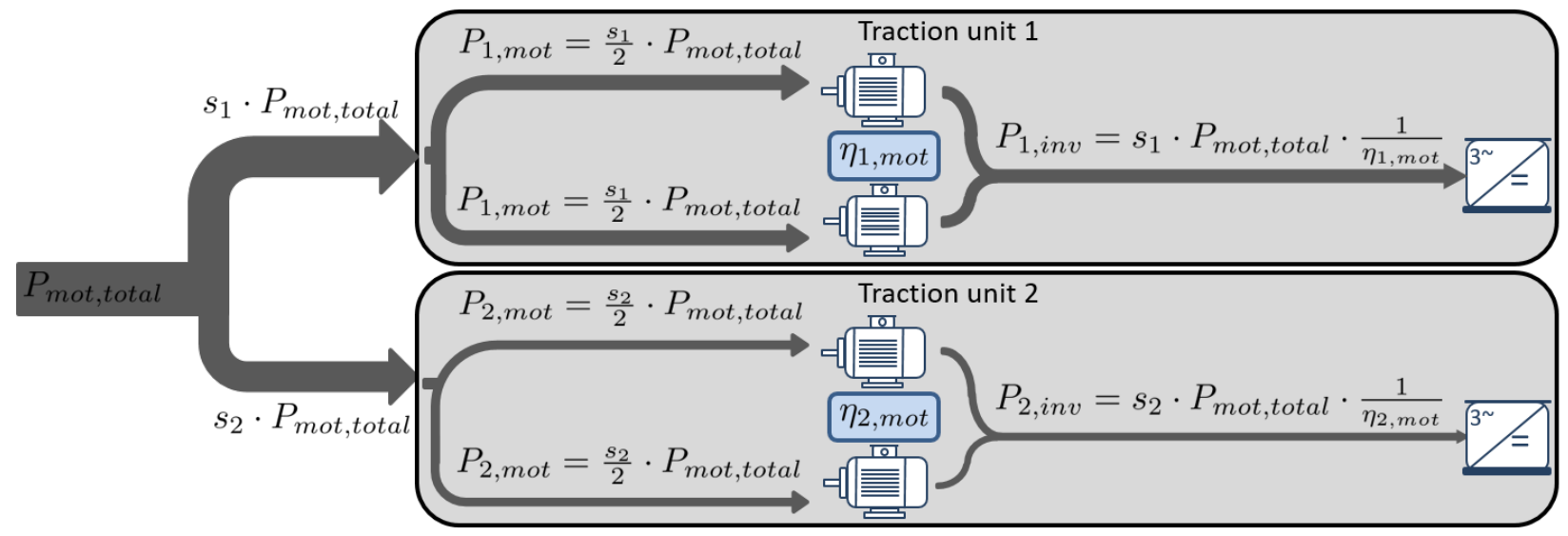

Figure 15. Demonstration example of the load distribution with $n_{m o t}=4$ and $n_{\text {inv }}=2(r=2)$.

To predict the most efficient splitting factors for the traction units, the line efficiency $\eta_{t u}$ of the traction unit is maximized by solving

$$
\eta_{t u}=\max _{\underline{s}}\left\{\eta_{m o t}\left(\underline{s}, P_{m o t, t o t a l}, \omega_{m o t}\right) \cdot \eta_{\text {inv }}\left(\underline{s}, P_{m o t}, \text { total }, \omega_{m o t}\right)\right\} .
$$

Here, the total efficiency of the motors $\eta_{\text {mot }}$ is given by

$$
\eta_{\text {mot }}=\frac{\sum_{i}^{n_{\text {mot }}}(\eta_{i, \text { mot }}(\overbrace{\frac{\overbrace{i}}{r} \cdot P_{\text {mot,total }}, \omega_{\text {mot }}}^{P_{i, \text { mot }}}) \cdot \overbrace{\frac{s_{i}}{r} \cdot P_{\text {mot,total }}}^{P_{i, \text { mot }}})}{P_{\text {mot }, \text { total }}},
$$


because the efficiency maps (according to Figure 5) have to be evaluated with the applied power $P_{i, m o t}$. In analogy, the efficiency of the inverters $\eta_{i n v}$ can be determined by

$$
\eta_{\text {inv }}=\frac{\sum_{i}^{n_{\text {inv }}}(\eta_{i, \text { inv }}(\overbrace{s_{i} \cdot P_{\text {mot, total }} \cdot \frac{1}{\eta_{i, \text { mot }}}}^{P_{i, \text { inv }}}, \omega_{\text {mot }}) \cdot \overbrace{s_{i} \cdot P_{\text {mot, total }} \cdot \frac{1}{\eta_{i, \text { mot }}}}^{P_{i, \text { mot }}})}{P_{\text {mot, total }}} .
$$

As a result of the load-distribution, the single traction units are running at different loads to avoid a low-load operation. The idle losses of the traction motors and inverters, however, still affect the total energy consumption.

The implementation of the presented switch-off as well as of the load-distribution technique is depicted in Figure 16. As expected, the simulation results indicate that for phases with a high power request, the maximum number of motors is employed (especially during acceleration and braking phases), whereas for lower-power requests, the number of applied motors can be reduced (especially during cruising phases). In particular, during coasting or standstill phases all traction drives are switched off $\left(n_{m o t}=n_{i n v}=0\right)$. Beside the energy savings based on the avoidance of idle losses, the simulation results also underline that the line efficiency $\eta_{t u}=\eta_{\text {mot }} \cdot \eta_{i n v}$ can be increased for a major part of the drive cycle. These results provide a strong indication that this technique offers huge potential for energy savings.

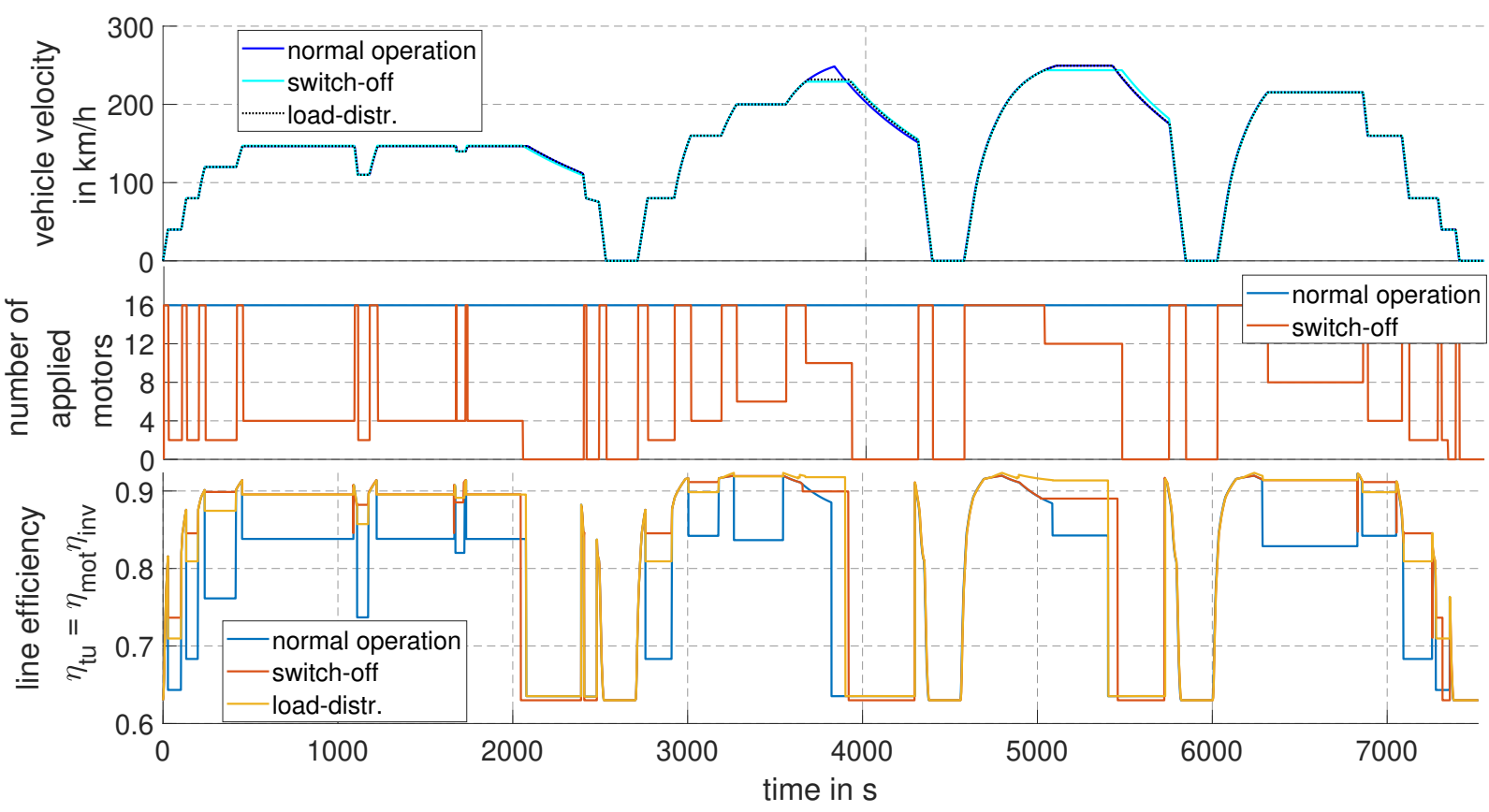

Figure 16. Application of traction unit switch-offs and the load distribution technique.

In addition, the implementation of the load distribution without a switch-off of the traction units results in an increased line efficiency of the traction unit. Despite the fact that the idle losses of the motors and inverters still affect the total energy losses, this technique results in a decreased total energy consumption (see Section 6).

\section{The Influence of the Operating Strategy regarding the Optimized Driving Strategy}

As already indicated in the velocity profiles in Figure 16, the applied operating strategy has an influence on the energy-optimal driving style. Especially for the drive cycle in the second segment, the energy-optimal velocity trajectories differ regarding the applied operating strategy. To underline this effect, Figure 17 presents the total energy consumption depending on different amounts of coasting. For this purpose, the total 
energy consumption was evaluated for different values of $b_{c} \in\left\{b_{c, \text { min }}, 1\right\}\left(b_{c}=b_{c, \text { min }}\right.$ : maximize coasting, $b_{c}=b_{1}$ : no coasting) for each station-to-station drive cycle.

Here, the red circles " $\circ$ " indicate a set of possible solutions resulting in an energyoptimized driving style (the global optimum only differs by minor energy values compared to the selected solution set). As there are several possible driving strategies optimizing the energy consumption, representative velocity profiles are depicted in Figure 18. The corresponding coasting parameters are marked by the black plus symbols "+" in Figure 17.
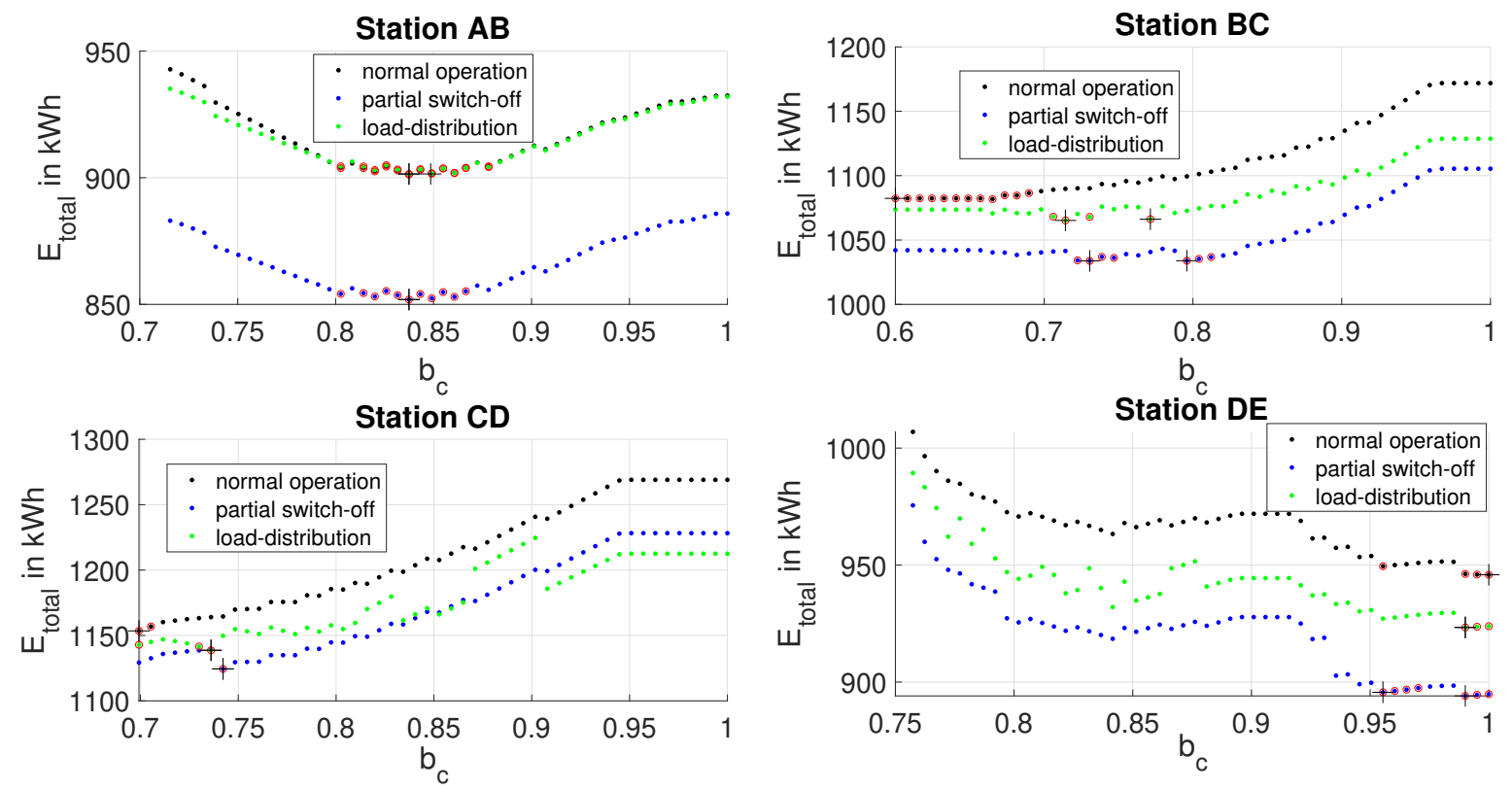

Figure 17. The total energy consumption for single station-to-station drive cycles depending on the amount of coasting $\left(b_{c}=b_{c, \text { min }}\right.$ : maximize coasting, $b_{c}=b_{1}:$ no coasting). The red circles "o" indicate the range with energy efficient driving styles. The black plus symbols "+" mark the presented trajectory profiles in Figure 18.

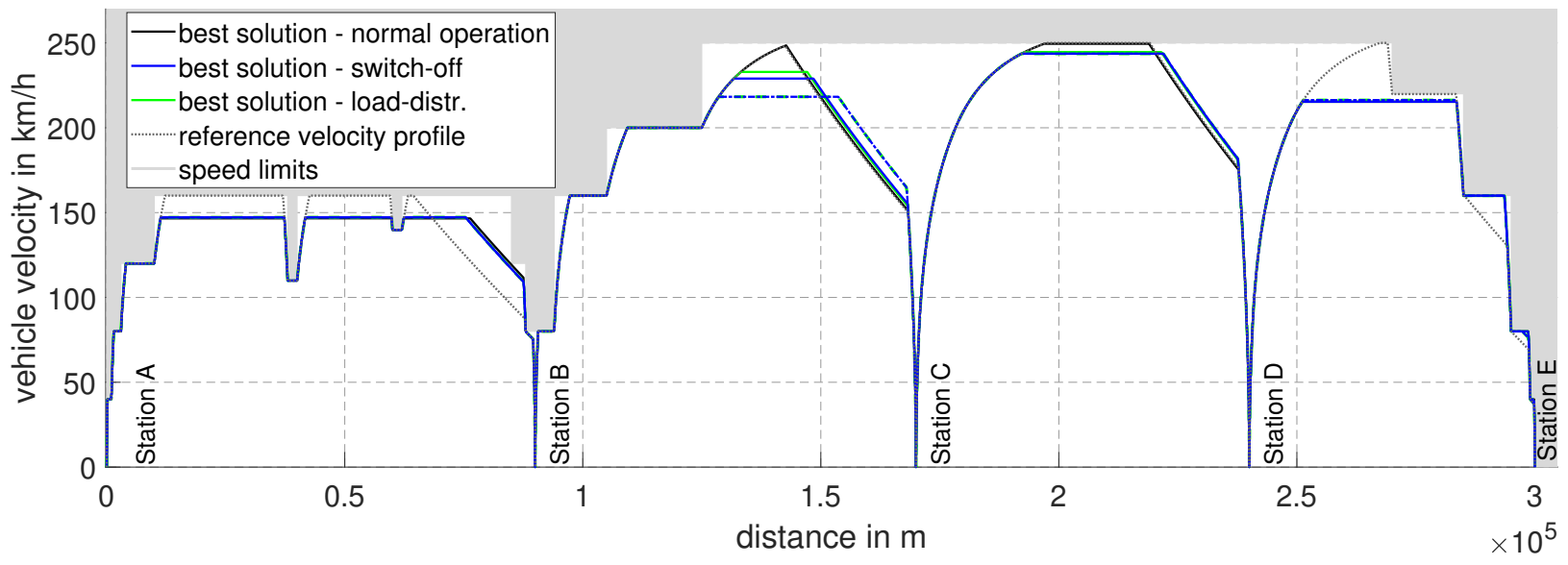

Figure 18. Different velocity profiles representing the energy-optimized driving style for different operating strategies. The dotted lines indicate an alternative driving style with only minor differences regarding the energy consumption.

To show the potential energy savings, the optimized driving strategy for each operating strategy was evaluated. The total energy consumptions for all three operating strategies are stated in Table 2 . The corresponding optimal solutions $b_{c}^{*}$ and $p_{v}^{*}$ are summarized in Table A3. 
Table 2. Energy savings due to energy-optimized operating strategies.

\begin{tabular}{|c|c|c|c|c|c|c|c|}
\hline \multirow[b]{2}{*}{ Segment } & \multicolumn{3}{|c|}{ Energy Consumption in $\mathrm{kWh}$} & \multicolumn{2}{|c|}{$\begin{array}{l}\text { Total Energy } \\
\text { Savings in } \mathrm{kWh}\end{array}$} & \multicolumn{2}{|c|}{$\begin{array}{l}\text { Total Energy } \\
\text { Savings in } \%\end{array}$} \\
\hline & $\begin{array}{l}\text { Normal } \\
\text { Operation }\end{array}$ & $\begin{array}{l}\text { Traction- } \\
\text { Unit } \\
\text { Switch-Off }\end{array}$ & $\begin{array}{l}\text { Load- } \\
\text { Distribution } \\
\text { Without } \\
\text { Switch-Off }\end{array}$ & $\begin{array}{l}\text { Normal vs. } \\
\text { Switch-Off }\end{array}$ & $\begin{array}{l}\text { Normal vs. } \\
\text { Load-Dist. }\end{array}$ & $\begin{array}{l}\text { Normal vs. } \\
\text { Switch-Off }\end{array}$ & $\begin{array}{l}\text { Normal vs. } \\
\text { Load-Dist. }\end{array}$ \\
\hline Station $\mathrm{AB}$ & 902 & 852 & 901 & $\approx 50$ & $\approx 1$ & $\approx 5.5$ & $\approx 0$ \\
\hline Station BC & 1080 & 1034 & 1065 & $\approx 46$ & $\approx 15$ & $\approx 4$ & $\approx 1.5$ \\
\hline Station CD & 1158 & 1124 & 1139 & $\approx 34$ & $\approx 19$ & $\approx 3$ & $\approx 1.5$ \\
\hline Station DE & 946 & 894 & 923 & $\approx 52$ & $\approx 23$ & $\approx 5.5$ & $\approx 2.5$ \\
\hline $\begin{array}{l}\text { Total net } \\
\text { energy }\end{array}$ & 4086 & 3904 & 4029 & $\approx 182$ & $\approx 57$ & $\approx 4.5$ & $\approx 1.5$ \\
\hline
\end{tabular}

Besides the energy savings based on the energy-optimal driving strategy, the load distribution strategies allow for additional energy savings of $1.5-4.5 \%$ for each total drive cycle.

This also suggests that the application of the load distribution techniques allows for a reduction of the coasting phases related to an avoidance of high-speed driving phases (e.g., in segment 2, the maximum velocity is reduced from $v_{\max }=250 \mathrm{~km} / \mathrm{h}$ to $v_{\max } \approx 220 \mathrm{~km} / \mathrm{h}$ ). This also provides benefits in terms of mechanical wear and ambient noise as well as in-vehicle noise. Additionally, the decreased amount of acceleration is advantageous in terms of passenger comfort.

\section{Conclusions and Outlook on Future Research}

In this paper, energy-optimization strategies for railway vehicles were investigated that were based on two main pillars:

i. An optimization regarding the energy-optimal driving strategy for railway vehicles was presented.

ii. The traction chain structure of the railway topology was exploited to implement a load distribution between the traction units running in parallel.

In addition to the potential energy savings resulting from each of these two strategies, the correlation between their techniques was also investigated. It was shown that the application of load-distribution techniques, either by a switch-off of parallel traction units or by a load-distribution between active units, can affect the energy-optimal driving style. By evaluating and analyzing the energy consumption for different driving strategies, it becomes obvious that the application of load-distribution techniques allows for an increased set of energy-optimized velocity profiles, allowing for a range of driving styles without an increase in the energy consumption.

The resulting velocity profiles can be utilized as a reference signal for the implementation of a velocity feedback control in a real-world application. Additionally, this methodology is not only applicable for planning the drive cycle in advance; with an adjustment of the boundary conditions (e.g., a reduced driving time in case of a delay), the method is capable of calculating a new velocity profile in a few minutes, to compensate for the delay. In future work, the variety of possible solutions can be utilized for an implementation of multi-objective optimization approaches. Further topics of interest (e.g., noise, mechanical wear, passenger comfort, thermodynamic effects, economic operation, etc.) can be considered in the joint optimization of the operating strategy as well as the driving strategy.

Additionally, the extension of the traction chain topology is of great interest. The operating strategy for the application of an additional energy storage system (e.g., a battery system) or a fuel-cell topology, may also have an effect on the energy-optimal driving style. 
Author Contributions: Conceptualization, L.P. and H.A.; methodology, L.P.; software, L.P.; validation, L.P.; investigation, L.P.; resources, H.A.; writing-original draft preparation, L.P.; writingreview and editing, H.A. and R.P.; visualization, L.P.; supervision, H.A. All authors have read and agreed to the published version of the manuscript.

Funding: This research received no external funding.

Institutional Review Board Statement: Not applicable.

Informed Consent Statement: Not applicable.

Data Availability Statement: The used railway data and simulation package is available at the OPEUS website [16].

Acknowledgments: The authors gratefully acknowledge the support and contribution provided by the partners of the OPEUS (EU grant agreement No 730827) and FINE-1 (EU grant agreement No 730818) projects, regarding the development and validation of the OPEUS tool.

Conflicts of Interest: The authors declare no conflicts of interest.

Sample Availability: Samples of the compounds [8-10,12-15,17,21] are available from the authors.

\author{
Abbreviations \\ The following abbreviations are used in this manuscript: \\ MDPI Multidisciplinary Digital Publishing Institute \\ FFA Firefly algorithm \\ AC Alternating current \\ DC Direct current \\ HS250 High-speed train service with maximum velocity of $250 \mathrm{~km} / \mathrm{h}$
}

\title{
Appendix A. Parameters of the Railway Vehicle
}

This section provides the implemented simulation parameters for the presented railway vehicle according to the model presented in Section 2. All the implemented parameters are elaborated in [18] and are summarized in Table A1 and Table A2.

Table A1. Parameters for the simulation model of the mechanical railway vehicle.

\begin{tabular}{lll}
\hline Description & Symbol & Value \\
\hline Total mass & $M$ & $495 \times 10^{3} \mathrm{~kg}$ \\
Rotation factor & $k_{\text {rot }}$ & 0.04 \\
Specific running resistance & $c_{0}$ & $3200 \mathrm{~N}$ \\
Specific running resistance, constant term & $c_{1}$ & $30 \mathrm{~N} /(\mathrm{km} / \mathrm{h})$ \\
Specific running resistance, quadratic term & $c_{2}$ & $0.5 \mathrm{~N} /(\mathrm{km} / \mathrm{h})^{2}$ \\
Maximum velocity & $v_{\text {max }}$ & $250 \mathrm{~km} / \mathrm{h}$ \\
Initial velocity of maximum power hyperbola & $v_{1}$ & $80 \mathrm{~km} / \mathrm{h}$ \\
traction & & \\
Velocity to begin of power reduction traction & $v_{2}$ & $200 \mathrm{~km} / \mathrm{h}$ \\
Maximum traction force at the wheel & $F_{\text {wheel }}$ & $200 \mathrm{~N}$ \\
\hline
\end{tabular}


Table A2. Parameters for the simulation model of the electrical railway vehicle.

\begin{tabular}{|c|c|c|}
\hline Description & Symbol & Value \\
\hline \multicolumn{3}{|c|}{ Traction motors } \\
\hline Number of motors & $n_{m o t}$ & 16 \\
\hline Maximum traction of the motor & $T_{m o t, m a x}$ & $2000 \mathrm{Nm}$ \\
\hline Maximum power of the motor & $P_{\operatorname{mot}, \max }$ & $500 \mathrm{~kW}$ \\
\hline Power losses during no-load operation & $P_{\text {mot, }, \text { idle }}$ & $5 \mathrm{~kW}$ \\
\hline Efficiency characteristic & $\eta_{m o t}$ & $\begin{array}{l}\text { see generic efficiency } \\
\text { map in [18] }\end{array}$ \\
\hline \multicolumn{3}{|c|}{ Traction inverter } \\
\hline Number of inverters & $n_{i n v}$ & 8 \\
\hline Maximum power of the inverter & $P_{\text {inv, } \max }$ & $1000 \mathrm{~kW}$ \\
\hline Power losses during no-load operation & $P_{\text {inv, idle }}$ & $1 \mathrm{~kW}$ \\
\hline Efficiency characteristic & $\eta_{i n v}$ & $\begin{array}{l}\text { see generic efficiency } \\
\text { map in [18] }\end{array}$ \\
\hline \multicolumn{3}{|c|}{ Absorption circuit } \\
\hline Number of absorption circuits & $n_{a c}$ & 2 \\
\hline Maximum power of the absorption circuit & $P_{a c, \max }$ & $4000 \mathrm{~kW}$ \\
\hline Power losses during no-load operation & $P_{a c, i d l e}$ & $0 \mathrm{~kW}$ \\
\hline Efficiency characteristic & $\eta_{a c}$ & $\begin{array}{l}\text { see generic efficiency } \\
\text { map in [18] }\end{array}$ \\
\hline \multicolumn{3}{|c|}{ Line converter } \\
\hline Number of converters & $n_{l c}$ & 2 \\
\hline Maximum power of the converter & $P_{l c, \max }$ & $4000 \mathrm{~kW}$ \\
\hline Power losses during no-load operation & $P_{l c, \text { idle }}$ & $2 \mathrm{~kW}$ \\
\hline Efficiency characteristic & $\eta_{l c}$ & $\begin{array}{l}\text { see generic efficiency } \\
\text { map in [18] }\end{array}$ \\
\hline \multicolumn{3}{|c|}{ Transformer } \\
\hline Number of transformers & $n_{\text {trans }}$ & 2 \\
\hline Maximum power of the transformer & $P_{\text {trans, } \max }$ & $4200 \mathrm{~kW}$ \\
\hline Power losses during no-load operation & $P_{\text {trans,idle }}$ & $20 \mathrm{~kW}$ \\
\hline Efficiency characteristic & $\eta_{\text {trans }}$ & $\begin{array}{l}\text { see generic efficiency } \\
\text { map in [18] }\end{array}$ \\
\hline \multicolumn{3}{|c|}{ Electrical auxiliaries } \\
\hline $\begin{array}{l}\text { Auxiliary power for a spring/autumn sea- } \\
\text { son }\end{array}$ & $P_{a u x}$ & $200 \mathrm{~kW}$ \\
\hline \multicolumn{3}{|c|}{ Auxiliary converter } \\
\hline Number of auxiliary converters & $n_{\text {auxc }}$ & 4 \\
\hline Maximum power of the auxiliary converter & $P_{\text {auxc }, \max }$ & $100 \mathrm{~kW}$ \\
\hline Power losses during no-load operation & $P_{\text {auxc, idle }}$ & $1 \mathrm{~kW}$ \\
\hline Efficiency characteristic & $\eta_{\text {auxc }}$ & $\begin{array}{l}\text { see generic efficiency } \\
\text { map in [18] }\end{array}$ \\
\hline
\end{tabular}

\section{Appendix B. Parameters for the Firefly Optimization Approach}

This section provides an overview of the parameters of the firefly optimization approach in Table A3. Additionally, the optimal solutions of the optimization parameters are stated for every station-to-station drive. 
Table A3. Parameters for the applied firefly optimization method.

\begin{tabular}{|c|c|c|}
\hline Description & Symbol & Value \\
\hline Number of applied particles & $n_{F F}$ & 40 \\
\hline Number of iterations & $N_{\text {max }, \text { ite }}$ & 40 \\
\hline \multicolumn{3}{|c|}{ Optimal solutions for the advanced driving profiles } \\
\hline \multicolumn{3}{|c|}{ Optimal solutions for the normal operation } \\
\hline Section A-B & & \\
\hline Parameter to define the maximum desired velocity & $p_{v, 1}$ & 0.9161 \\
\hline $\begin{array}{l}\text { Parameter to define the distance to apply coasting } \\
\text { Section B-C }\end{array}$ & $b_{c, 1}$ & 0.8485 \\
\hline Parameter to define the maximum desired velocity & $p_{v, 2}$ & 0.9941 \\
\hline $\begin{array}{l}\text { Parameter to define the distance to apply coasting } \\
\text { Section C-D }\end{array}$ & $b_{c, 2}$ & 0.5994 \\
\hline Parameter to define the maximum desired velocity & $p_{v, 3}$ & 0.9980 \\
\hline $\begin{array}{l}\text { Parameter to define the distance to apply coasting } \\
\text { Section D-E }\end{array}$ & $b_{c, 3}$ & 0.6992 \\
\hline Parameter to define the maximum desired velocity & $p_{v, 4}$ & 0.8613 \\
\hline Parameter to define the distance to apply coasting & $b_{c, 4}$ & 1 \\
\hline
\end{tabular}

Optimal solutions for the application of traction component switch-off

Section A-B

Parameter to define the maximum desired velocity

$\begin{array}{ll}p_{v, 1} & 0.9199 \\ b_{c, 1} & 0.8374\end{array}$

Parameter to define the distance to apply coasting

Section B-C

Parameter to define the maximum desired velocity

Parameter to define the distance to apply coasting

Section C-D

Parameter to define the maximum desired velocity

Parameter to define the distance to apply coasting

Section D-E

Parameter to define the maximum desired velocity

Optimal solutions for the application of load-distribution

Section A-B

Parameter to define the maximum desired velocity

Parameter to define the distance to apply coasting

Section B-C

$b_{c, 1}$

Parameter to define the maximum desired velocity

Parameter to define the distance to apply coasting

Section C-D

Parameter to define the maximum desired velocity

Parameter to define the distance to apply coasting

Section D-E

Parameter to define the maximum desired velocity 


\section{References}

1. Thrun, S.; Burgard, W.; Fox, D. Probabilistic Robotics; Intelligent Robotics and Autonomous Agents, The MIT Press: Cambridge, MA, USA, 2005.

2. Ludwig, J. Electronic horizon: Flexible implementation of predictive driver assistance features. In 15. Internationales Stuttgarter Symposium; Springer Vieweg: Wiesbaden, Germany, 2015.

3. Taguchi, S.; Koide, S.; Yoshimura, T. Online map matching with route prediction. IEEE Trans. Intell. Transp. Syst. 2019, 20, 338-347. [CrossRef]

4. Hansen, I.; Pachl, J. Railway Timetabling and Operations, 2nd ed.; Eurailpress: Hamburg, Germany, 2014

5. Howlett, P. The optimal control of a train. Ann. Oper. Res. 2000, 98, 65-87. [CrossRef]

6. Franke, R.; Terwiesch, P.; Meyer, M. An algorithm for the optimal control of the driving of trains. In Proceedings of the 39th IEEE Conference on Decision and Control, Sydney, NSW, Australia, 12-15 December 2000.

7. Franke, R.; Terwiesch, P.; Meyer, M. Optimal control of the driving of trains. at-Automatisierungstechnik 2002, 50, 606-613. [CrossRef]

8. Powell, J.; Palacin, R. A comparison of modelled and real-life driving profiles for the simulation of railway vehicle operation. Transp. Plan. Technol. 2015, 38, 78-93. [CrossRef]

9. Leska, M.; Prabel, R.; Rauh, A.; Aschemann, H. Simulation and optimization of the longitudinal dynamics of parallel hybrid railway vehicles. In FORMS/FORMAT; E. Schnieder, G.Tarnai, Ed.; Springer: Berlin/Heidelberg, Germany, 2011; Volume 281, pp. 155-164.

10. Leska, M.; Grüning, T.; Aschemann, H.; Rauh, A. Optimization of the longitudinal dynamics of parallel hybrid railway vehicles. In Proceedings of the IEEE Multi-Conference on Systems and Control, Dubrovnik, Croatia, 3-5 October 2012.

11. ShangGuan, W.; Yan, X.; Cai, B.; Wang, J. Multiobjective optimization for train speed trajectory in CTCS high-speed railway with hybrid evolutionary algorithm. IEEE Trans. Intell. Transp. Syst. 2015, 16, 2215-2225. [CrossRef]

12. Pröhl, L.; Aschemann, H. Energy optimal trajectory planning for electrically driven railway vehicles with particle swarm optimization. In Proceedings of the 2019 IEEE 15th International Conference on Control and Automation (ICCA), Edinburgh, UK, 16-19 July 2019; pp. 423-428. [CrossRef]

13. Pröhl, L.; Aschemann, H. Multimodal optimization for the trajectory planning of railway vehicles. In Proceedings of the 2020 IEEE Congress on Evolutionary Computation (CEC), Glasgow, UK, 19-24 July 2020.

14. Leska, M.; Aschemann, H.; Melzer, M.; Meinert, M. Comparative calculation of the fuel optimal operating strategy for diesel hybrid railway vehicles. Int. J. Appl. Math. Comput. Sci. 2017, 27, 323-336. [CrossRef]

15. Leska, M.; Prabel, R.; Aschemann, H.; Rauh, A. Optimal operating strategy for hybrid railway vehicles based on a sensitivity analysis. IFAC Proc. Vol. IFAC-Pap. 2014, 19, 942-947. [CrossRef]

16. Shift2Rail project OPEUS. Modelling and strategies for the assessment and OPtimisation of Energy USage aspects of rail innovation. project reference: 730827. 2019. Available online: http://www.opeus-project.eu/ (accessed on 19 January 2021).

17. Dittus, H.; Völker, H.; Pröhl, L.; Aschemann, H.; Heibl, S.; Palacin, R. Energy assessment in Shift2Rail european rail research project. In Proceedings of the 12th World Congress on Railway Research-Congress Proceedings WCRR 2019, Tokyo, Japan, 28 October-1 November 2019.

18. Ernst J. and FINE1 Energy group. FINE1 Deliverable D3.1-Energy Baseline. 2018. Available online: https://projects.shift2rail. org/s2r_ipcc_n.aspx?p=FINE1 (accessed on 19 January 2021).

19. Guzella, L.; Sciarretta, A. Vehicle Propulsion Systems, 2nd ed.; Springer: Berlin/Heidelberg, Germany, 2007.

20. Rochard, B.; Schmid, F. A review of methods to measure and calculate train resistances. Proc. Inst. Mech. Eng. Part F J. Rail Rapid Transit 2000, 214, 185-199. [CrossRef]

21. Shift2Rail project OPEUS. OPEUS Simulation Package, OPEUS Deliverable Report D2.1. Shift2Rail Website-OPEUS Project. 2017. Available online: https://projects.shift2rail.org/s2r_ipcc_n.aspx?p=OPEUS (accessed on 19 January 2021)

22. Yang, X. Firefly algorithms for multimodal optimization. In Stochastic Algorithms: Foundations and Applications; Watanabe, O., Zeugmann, T., Eds.; Springer: Berlin/Heidelberg, Germany, 2009. 